\title{
PENDIDIKAN BELA NEGARA BAGI SANTRI PESANTREN DI CIKALONG KABUPATEN TASIKMALAYA
}

\author{
EDUCATION STATE DEFANDING FOR SANTRI PESANTREN \\ IN CIKALONG, TASIKMALAYA DISTRICT
}

\author{
1) Akhmad Satori, ${ }^{2)}$ Edi Kusmayadi \\ 1)2) Jurusan Ilmu Politik FISIP Universitas Siliwangi, \\ Jl. Siliwangi No. 24 Tasikmalaya 46115 \\ email :akhmadsatori@unsil.ac.id
}

\begin{abstract}
ABSTRAK
Tujuan kegiatan ini adalah memberikan pemahaman tentang pendidikan bela negara bagi santri dan pelajar dan pendidikan politik yang baik dan beretika, sehingga siswa atau santri terbentuk karakter yang secara rasional memahami politik secara subtansial.Metode yang digunakan dalam kegiatan ini yaitu dengan pemberian materi dan diskusi dengan menambahkan tayangan multimedia.Pemberian materi ditekankan pada pendidikan tentang pemahaman nilai-nilai filosofis wawasan kebangsaan dan Pancasila yang mampu membangkitkan semangat dan membentuk karakter santri atau siswa yang berakhlak atau bermoral sesuai dengan nilai-nilai filosofis Pancasila.Pemahaman karakter wawasan kebangsaan sebagai sebuah pendidikan dalam penerapannya, harus dilakukan secara bertahap dan konsisten, apalagi di tengah situasi dimana rasa kebangsaan yang melekat pada tiap generasi muda kian tipis sehingga upaya pembangunan manusia Indonesia yang berakhlak budi pekerti yang mulia dapat diwujudkan. Untuk mengukur keberhasilan kegiatan dilakukan pra test dan post test pemahaman materi dan terdapat peningkatan pemahaman mengenai bela negara dan wawasan kebangsaanoleh santri.
\end{abstract}

Kata Kunci :Pendidikan Bela Negara, Wawasan Kebangsaan, Pesantren, Santri

\section{ABSTRACT}

The purpose of this activity is to provide a deeper understanding of Bela Negara's education for santri and students, and understand good and ethical political education, so that students or santri will form characters that rationally understand politics substantially. The method used in this activity is by giving the material and discussion by adding multimedia impressions. The giving of matter is emphasized on education about understanding the philosophical values of nationalism and Pancasila insight that is able to arouse the spirit and form the character of santri or students who have moral or moral according to the philosophical values of Pancasila. Understanding the character of national insight as an education in its application, should be done gradually and consistently, especially in the midst of a situation where the sense of nationality inherent in each younger generation thinner so that the human development efforts of Indonesia with noble character noble character can be realized. To measure the success of the activities carried out pre-test and post test of material understanding and there is increasing understanding of the state defending and insight of nationality by santri.

Keywords: State Defense Education, National Insight, Pesantren, Santri

Submitted : 23 Agustus $2017 \quad$ Revision : 26 Mei $2018 \quad$ Accepted : 4 Juni 2018

\section{PENDAHULUAN}

Persoalan sosial politik bangsa Indonesia dewasa ini semakin memprihatinkan, pengaruh globalisasi yang mengusung nilai kebebasan yang individualistik mendorong berkembangnya sikap pragmatik, konsumeristik, hedonistik, dan materialistik telah mengabaikan nilai-nilai luhur bangsa seperti gotong royong, kekeluargaan, kerukunan dan kebersamaan sebagai 
pencerminan wawasan kebangsaan. Gejala ini terlihat dengan adanya berbagai kasus seperti banyaknya remaja yang sudah menggunakan narkoba, kasus-kasus korupsi, kolusi, nepotisme, ancaman terorisme semakin menguat.

Persoalan selanjutnya adalah meningkatnya intoleransi di masyarakat Indonesia. Persoalan ini punya kaitan dengan masalah kepribadian bangsa.Politik penyeragaman pada masa lalu dinilai telah mengikis karakter Indonesia dan meminggirkan kebudayaan lokal.Jati diri bangsa terkoyak oleh merebaknya konflik sektarian dan berbagai bentuk intoleransi.

Terkikisnya nilai-nilai karakter pelajar dan pemuda untuk jujur, bertanggungjawab, menghormati, serta tindakan positif lainnya.Karena minimnya pendidikan karakter yang diterapkan secara berkesinambungan dan serius.Dalam konteks ini pembelajaran Bela Negara diharapkan dapat memperkuat karakter untuk berkiprah di masyarakat dengan membawa nilai-nilai luhur dan nilai nilai kebangsaan.

Sementara dalam pengabdian pada masyarakat ini, difokuskan di wilayah Tasikmalaya yang mempunyai label "kota santri" yang terdapat ratusan pesantren di wilayah Priangan Timur ini.

Pondok Pesantren merupakan lembaga studi Islam yang punya nilai historis terhadap gerakan sosial keagamaan (Dhofier, 2002). Lembaga ini merupakan lembaga pendidikan Islam tertua di Indonesia.Maka wajarlah apabila banyak kalangan yang menyebutnya sebagai "Bapak" pendidikan Islam di negara yang mayoritas penduduknya umat Islam ini.Pondok pesantren lahir karena adanya tuntutan dan kebutuhan masyarakat, karena pada zaman dahulu belum ada lembaga pendidikan formal yang mengajarkan pendidikan agama.(Basri, 2001).

Pada dasarnya pondok pesantren bukan hanya sekedar lembaga pendidikan.Pesantren juga merupakan medium budaya dalam kehidupan
masyarakat.Namun demikian, sebagaimana dikemukakan oleh KH. Abdurrahman Wahid, jarang sekali orang yang berpandangan demikian. Pondok pesantren bukan hanya lembaga yang berfokus pada pendidikan intelektual saja, akan tetapi juga, pendidikan spiritual, pendidikan moral, dan lembaga pendidikan sosial kemasyarakatan (Mustofa, 2012)

Pesantren mendidik masyarakat kehidupan praktis di masyarakat dan bagaimana seorang santri menjalankan peran sosial dalam masyarakat.Sebagai lembaga pendidikan dan perantara kebudayaan masyarakat, pondok pesantren dapat berperan aktif dalam kehidupan sosial masyarakat termasuk peran politik.Pesantren mempunyai aset yang cukup handal dan tidak bisa diremehkan. Aset-aset ini bisa diarahkan untuk memacu kemajuannya, akan tetapi apabila ada salah langkah dalam pengelolan asset dan memainkan perannya maka tidak mustahil yang terjadi adalah sebaliknya, ia akan ditinggalkan oleh simpatisan dan civitas akademikanya.

Aset Pesantren belakangan ini seringkali menjadi target politik kekuasaan. Pesantren dewasa ini tengah dihadapkan pada pusaran politik praktis, banyak dari pesantren yang terbuka kepada politik, bahkan ada pula yang terlibat langsung dengan politik praktis.Kelompok ini membuka pintu (lebar-lebar) kepada para elit politik atau pejabat pemerintahan.Pengasuh pesantren juga bersedia berkunjung ke kediaman mereka. Dalam konteks ini pendidikan politik dan kesadaran wawasan kebangsaan berdasarkan nilai-nilai Pancasila perlu dilakukan di pesantren, agar pesantren bisa menempatkan posisi politik yang paling tepat bagi bangsa Indonesia.

Kecamatan Cikalong merupakan salah satu kecamatan yang berada di wilayah administrasi Kabupaten Tasikmalaya. Kecamatan Cikalong ini merupakan sebuah kecamatan yang mempunyai luas wilayah yang cukup luas yakni mencapai $13629,5 \mathrm{~km}^{2}$. Secara 
Akhmad Satori, Edi Kusmayadi

geografis Kecamatan Cikalong berada di dataran rendah dengan ketinggian rata-rata permukaan tanah adalah 25 meter diatas permuakaan laut. Kecamatan Cikalong terbagi kedalam 13 desa yaitu Desa Mandalajaya, Cikalong, Cikancra, Tonjongsari, Singkir, Panyiaran, Cibeber, Cidadali, Kubangsari, Cikadu, Sindangjaya, Kalapagenep dan Cimanuk.(BPS Kab. Tasikmalaya, 2016)

Desa yang mempunyai luas wilayah yang paling besar adalah Desa Kubangsari dengan luas wilayah mencapai 1715.35 $\mathrm{Km}^{2}$ atau $15,9 \%$ dari seluruh luas wilayah Kecamatan Cikalong dan desa yang paling kecil adalah Desa Cikancra dengan luas wilayahnya hanya mencapai $561.31 \mathrm{Km}^{2}$ atau $7,2 \%$ dari jumlah keseluruhan Kecamatan Cikalong. (BPS Kab. Tasikmalaya, 2016)

Di daerah ini, seperti halnya daerah lain di Kabupaten Tasikmalaya juga merupakan daerah santri atau pelajar agama Islam di pondok-pondok pesantren. Di kecamatan Cikalong menurut penelusuran peneliti setidaknya terdapat 23 pesantren yang tercatat diselenggarakan di wilayah ini, daftar pesantren bias dilihat dari Tabel 1. Berikut :

Tabel 1. Daftar Pondok Pesantren di Kecamatan Cisayong

\begin{tabular}{llcl}
\hline No & Nama Pesantren & $\begin{array}{c}\text { Jml } \\
\text { San } \\
\text { tri }\end{array}$ & \multicolumn{1}{c}{ Alamat } \\
\hline 1. & PP. Al Hidayah, & 238 & $\begin{array}{l}\text { Kp. Cilutung, } \\
\text { Ds. Cikalong }\end{array}$ \\
\hline 2. & PP. Al Ihlas, & 80 & $\begin{array}{l}\text { Kp. Citisuk, } \\
\text { Ds. Cibeber }\end{array}$ \\
\hline 3. & PP. Al Ihsan, & 68 & $\begin{array}{l}\text { Kp. Citisuk, } \\
\text { Ds. Cibeber }\end{array}$ \\
\hline 4. & PP. Al Mubarokah, & 404 & $\begin{array}{l}\text { Ds. Situpari, } \\
\text { Cikalong }\end{array}$ \\
\hline 5. & PP. Al-Hidayah, & 202 & Cikalong \\
\hline 6. & PP. Al- & 340 & Cikalong \\
Munawwarah, & & 51 & $\begin{array}{l}\text { Kp. Legok } \\
\text { Picung, }\end{array}$ \\
\hline 7. & PP. As Syifa, & 141 & Sindangjaya \\
\hline 8. & PP. Bahrul Huda, \\
\hline
\end{tabular}

\begin{tabular}{|c|c|c|}
\hline 9. PP. Darussalam, & 140 & $\begin{array}{l}\text { Cipancur, Ds. } \\
\text { Cidadali }\end{array}$ \\
\hline 10. PP. Khaerul Ulum, & 401 & $\begin{array}{l}\text { Ds. Cibeber } \\
\text { Cikalong }\end{array}$ \\
\hline $\begin{array}{l}\text { 11. PP. Mathla'ul } \\
\text { ulum, }\end{array}$ & 100 & $\begin{array}{l}\text { Karangtawula } \\
\text { n, Cikalong }\end{array}$ \\
\hline 12. PP. Miftahul Falah, & 10 & $\begin{array}{l}\text { Tonjongsari, } \\
\text { Cikalong }\end{array}$ \\
\hline $\begin{array}{l}\text { 13. PP. Miftahul Huda } \\
92,\end{array}$ & 110 & $\begin{array}{l}\text { Cipatat, } \\
\text { Cikalong }\end{array}$ \\
\hline $\begin{array}{ll}\text { 14. PP. Miftahul Huda } \\
\text { VI, }\end{array}$ & 136 & Cikalong \\
\hline 15. PP. Nurul Huda, & 274 & $\begin{array}{l}\text { Bbk. Balong, } \\
\text { Cikalong }\end{array}$ \\
\hline 16. PP. Nurul Huda, & 72 & $\begin{array}{l}\text { Kubangsari, } \\
\text { Cikalong }\end{array}$ \\
\hline 17. PP. Nurul Ihsan, & 96 & Cikalong \\
\hline 18. PP. Riadul Huda II, & 135 & $\begin{array}{l}\text { Cijulang } \\
\text { Rahayu,Cikalo } \\
\text { ng }\end{array}$ \\
\hline $\begin{array}{l}\text { 19. PP. Riadul } \\
\text { Mutaalim, }\end{array}$ & 121 & $\begin{array}{l}\text { Barengkok, } \\
\text { Cikalong }\end{array}$ \\
\hline 20. PP. Sinar Sari, & 39 & $\begin{array}{l}\text { Cilele, } \\
\text { Cikadu,Cikalo } \\
\text { ng }\end{array}$ \\
\hline 21. PPP. Tajul Falah, & 304 & $\begin{array}{l}\text { Singkir, } \\
\text { Cikalong }\end{array}$ \\
\hline $\begin{array}{l}\text { 22. PP. Uswatun } \\
\text { Hasanah, }\end{array}$ & 122 & $\begin{array}{l}\text { Pagar alam, } \\
\text { Cikalong }\end{array}$ \\
\hline
\end{tabular}

Sumber : Wikipedia/pesantren/tasikmalaya

Kecamatan Cikalong termasuk daerah yang memiliki banyak pesantren, tercatat kurang lebih ada 23 pesantren yang berdiri di wilayah ini, tersebar di beberapa desa sampai pelosok kampung. Dari sumber Wikipedia dapat dilihat persebaran pesantren di setiap desa di kecamatan Cikalong sangat merata, artinya persebaran pesantren tidak hanya fokus pada satu wilayah saja, ini memberikan pemahaman bahwa secara umum, masyarakat kecamatan Cikalong sangat relegius, dilihat juga dari persebaran masjid yang banyak.

Pembelajaran Bela Negara diharapkan dapat memperkuat karakter untuk berkiprah di masyarakat dengan membawa nilai-nilai luhur dan nilai nilai kebangsaan.Dalam mengatur dan menyelenggarakan kehidupannya, Bangsa Indonesia tidak terlepas dari pengaruh interaksi dengan lingkungannya, baik 
dalam lingkup nasional, regional maupun global. Dalam upaya mencapai tujuan nasionalnya, bangsa Indonesia senantiasa dihadapkan pada berbagai bentuk Tantangan, Ancaman, Hambatan dan Gangguan (ATHG), baik yang secara langsung maupun tidak langsung dapat membahayakan integritas, identitas, kelangsungan hidup bangsa dan negara. Untuk itu, diperlukan keuletan dan ketangguhan yang mengandung kemampuan mengembangkan kekuatan nasional dalam aspek dan dimensi kehidupan nasional yang disebut bela negara. (Sulistyaningtyas, dkk., 2015)

Kegiatan pendidikan bela negara dan wawasan kebangsaan sudah dilaksanakan beberapa tahun terakhir, di Kota dan Kabupaten Tasikmalaya. Salah satu pengabdian masyarakat yang sudah dilaksanakan yakni: Pendidikan Politik dan Wawasan Kebangsaan Bagi Santri dan Pelajar di Ponpes Cipasung-Tasikmalaya (2015), Pemberdayaan Pendidikan Politik Bagi Perempuan di Cijinjeung Ciamis (2014), Meningkatkan Peran Pemilih Pemula pada Pemilu 2014 di Ponpes Miftahul Huda Cibeureum (2014), Pendidikan Wawasan Kebangsaan, Melalui Penguatan Nilai Budaya Lokal dalam Memperkuat Jati Diri Bangsa di Desa Tanjung Sari, Kecamatan Sukaresik Kabupaten Tasikmalaya (2013), dan Pendidikan Politik Bagi Perempuan" Desa Batu Sumur Manonjaya Kota Tasikmalaya (2010).Kemudian penelitian yang juga dilaksanakan adalah penelitian dengan judul Studi Pemetaan dan Pemecahan Masalah Dalam Implementasi Pendidikan Karakter Pada Institusi Pendidikan di Kota Tasikmalaya pada tahun 2014.

Dengan beberapa pelaksanaan pengabdian pada masyarakat dan penelitian pada beberapa tahun terakhir sesuai dengan tema saat ini, kami menganggap urgenitas mengenai pendidikan politik dan wawasan kebangsaan kepada masyarakat, khususnya bagi kalangan santri dan pelajar saat ini.Agar pemikiran dan pemahaman mengenai politik dan wawasan kebangsaan dilakukan secara rasionalitas.Kemudian kami memandang bahwa pendidikan politik dan wawasan kebangsaan ini memang terus dilakukan secara berkelanjutan dan berkesinambungan.

Berangkat dari analisis situasi di atas, Tim PPM menganggap pentingnya untuk memetakan kembali (maping problem) dan mencari solusi (problem solving) dalam implementasi pendidikan bela negara dan pendidikan nilai nilai kebangsaan dalam institusi pendidikan pesantren. Berdasarkan uraian di atas maka dapat diinventarisasi permasalahan Santri dan Pelajar sebagai Mitra kegiatan yang direncanakan, meliputi :1) Belum ada upaya untuk melakukan sosialisasi atau pelatihan dan pendidikan bela negara secara langsung bagi santri dan pelajar di pesantren; 2) belum pernah di berikan secara langsung pemahaman akan bela negara dan wawasan kebangsaan sangat penting dilakukan untuk bekal dan di masyarakat.

\section{METODE KEGIATAN}

Kegiatan Pendidikan Bela Negara bagi pelajar dan santri ini dilaksanakan selama dua hari tanggal 19 -20 Juli 2017. berlokasi di Pondok Pesantren Al Hidayah Cilutung Cikalong dan Majelis Ulama Indonesia Kecamatan Cikalong dengan metode yang digunakan: (1) Pemberian pelatihanPendidikan; (2) Dialog, Games dan Simulasi; (3) Focus Guidence Discusion (FGD) Pembuatan Modul; (4) Pra Test dan Post Test. Alat Penunjang Kegiatan ini antara lain:Infocus dan Layar, Laptop, Alat Tulis, dan KIT pelatihan.

Model pengabdian masyarakat ini menggunakan model pembelajaran masyarakat. Adapun pelaksanaan kegiatan ini diikuti oleh 50 (limapuluh) orang peserta yang mewakili santri dan Pelajar di lingkungan Pesantren dan pengurus Majelis Ulama Indonesia (MUI) Kecamatan Cikalong. 


\section{HASIL DAN PEMBAHASAN}

Target luaran kegiatan ini adalah pemahaman mengenai wawasan kebangsaan bagi kalangan santri dan pelajar di Pondok Pesantren.Dengan memahami dan mendalami wawasan kebangsaan ini, diharapkan para pelajar dan santri memiliki rasa Cinta Tanah Air dan Bangsa, meningkatkan rasa toleransi terhadap keanekaragaman (majemuk) masyarakat Indonesia.Serta adanya sikap saling hormat menghormati dan menghargai dikalangan pelajar dan santri, bahwa mereka merupakan bagian dari masyarakat secara umum. Dengan memberikan pemahaman ini karakter pelajar dan santri akan semakin meningkat dan menjadi bagian penting dari pembangunan bangsa Indonesia.Dalam konteks inilah Pendidikan bela negara dan wawasan Kebangsaan mendapatkan urgensinya.

Untuk membangun sikap moral dan kesadaran secara umum diperlukan pendidikan kesadaran bela negara. Mengingat dalam pendidikan kesadaran bela negara mendidikan nilai-nilai keutamaan warga negara, maka dapat digolongkan ke dalam pendidikan kewarganegaraan (civic education). Kesadaran bela Negara perlu lebih ditingkatkan atau dengan kata lain perlu dilakukan revitalisasi, karena adanya pengaruh globalisasi disegala aspek kehidupan bermasyarakat, berbangsa dan bernegara.(Budiwibowo, 2016 ).

Dalam Pra dan Post test diajukan 10 (sepuluh) pertanyaan pilihan ganda dengan penggolongan pada 5 (lima) aspek meliputi: (1) Pemahaman mengenai Identitas Nasional, (2) Pemahaman mengenai Pancasila, (3) Kewajiban Bela Negara, (4) Pemahaman Mengenai Wawasan Kebangsaan, (5) Sikap Terhadap Radikalisme. Dari 40 peserta dari santri maupun pelajar diambil 20 peserta sebagai kelompok sasaran untuk mengisi kuisioner pra dan post test dan didapatkan hasil dari tabel sebagai berikut :
Tabel. Hasil Pratest dan Posttest

\begin{tabular}{|c|c|c|c|c|}
\hline $\begin{array}{l}\mathbf{N} \\
\mathbf{0}\end{array}$ & $\begin{array}{l}\text { Santri/Sis } \\
\text { wa }\end{array}$ & $\begin{array}{l}\text { PostTe } \\
\text { st }\end{array}$ & $\begin{array}{l}\text { Pas } \\
\text { t } \\
\text { Tes } \\
\text { t }\end{array}$ & $\begin{array}{l}\text { Keterang } \\
\text { an }\end{array}$ \\
\hline 1 & A & 45 & 70 & meningkat \\
\hline 2 & B & 40 & 60 & meningkat \\
\hline 3 & $\mathrm{C}$ & 75 & 75 & tetap \\
\hline 4 & $\mathrm{D}$ & 50 & 65 & meningkat \\
\hline 5 & $\mathrm{E}$ & 55 & 70 & meningkat \\
\hline 6 & $\mathrm{~F}$ & 55 & 75 & meningkat \\
\hline 7 & $\mathrm{G}$ & 50 & 75 & meningkat \\
\hline 8 & $\mathrm{H}$ & 70 & 80 & meningkat \\
\hline 9 & $\mathrm{I}$ & 65 & 65 & meningkat \\
\hline 10 & $\mathrm{~J}$ & 55 & 70 & meningkat \\
\hline 11 & $\mathrm{~K}$ & 50 & 75 & meningkat \\
\hline 12 & $\mathrm{~L}$ & 50 & 80 & meningkat \\
\hline 13 & $\mathrm{M}$ & 60 & 85 & meningkat \\
\hline 14 & $\mathrm{~N}$ & 45 & 65 & meningkat \\
\hline 15 & $\mathrm{O}$ & 35 & 65 & meningkat \\
\hline 16 & $\mathrm{P}$ & 45 & 65 & meningkat \\
\hline 17 & Q & 75 & 90 & meningkat \\
\hline 18 & $\mathrm{R}$ & 60 & 75 & meningkat \\
\hline 19 & $S$ & 65 & 85 & meningkat \\
\hline 20 & $\mathrm{~T}$ & 50 & 75 & meningkat \\
\hline & $\begin{array}{c}\text { Skor Rata } \\
\text { Rata }\end{array}$ & 54,57 & $\begin{array}{l}73,2 \\
5\end{array}$ & \\
\hline
\end{tabular}

Hampir semua santri dan pelajar yang di jadikan kelompok sasaran meningkat skor pemahamannya mengenai identitas nasional, pancasila, wawasan kebangsaan dan bela negara serta dimintai sikap terhadap radikalisme dari pretest menunjukan skor rata rata yang di peroleh seluruh sampel adalah 54,57 dan setelah mendapatkan pelatihan dan penyuluhan skor rata rata naik menjadi 73,25 . Hal ini membuktikan bahwa terdapat peningkatan pemahaman terhadap nilai nilai wawasan kebangsaan dan bela negara.

Kekhawatiran akan degredasi moral dan merosotnya mental generasi muda Indonesia semakin terbukti, seiring pudarnya budaya bangsa akibat persaingan global, yang mengusung nilai kebebasan yang individualistik mendorong berkembangnya sikap pragmatik, konsumeristik, hedonisme,dan materialistik, yang mengabaikan nilai-nilai luhur bangsa seperti gotong royong, kekeluargaan, kerukunan dan kebersamaan 
sebagai pencerminan wawasan kebangsaan. Kekhawatiran tersebut dapat kita sadari betapa pentingnya implementasi pendidikan bela negara dan wawasan kebangsaan. (Andrias, 2016)

Kegiatan ini berupaya memberikan pemahaman lebih mendalam tentang pendidikan tentang pemahaman nilai-nilai filosofis wawasan kebangsaan dan Pancasila, mampu membangkitkan semangat dan membentuk karakter siswa yang berakhlak ataupun bermoral sesuai dengan nilai-nilai filosofis Pancasila. Pemahaman karakter wawasan kebangsaan sebagai sebuah pendidikan dalam penerapannya, harus dilakukan secara bertahap dan konsisten, apalagi di tengah situasi dimana rasa kebangsaan yang melekat pada tiap generasi muda kian tipis, perlu dicetuskan pendidikan nilai nilai kebangsaan wujud penanaman karakter kebangsaan kepada seluruh lapisan masyarakat sehingga upaya pembangunan manusia Indonesia yang berakhlak budi pekerti yang mulia dapat diwujudkan.

Salah satu strategi dalam pelaksanaan kegiatan ini yaitu dengan model pembelajaran masyarakat.Model pembelajaran masyarakat yaitu suatu Kegiatan yang ditujukan untuk belajar bersama masyarakat atau menguatkan potensi, kemampuan, potensi dan asset masyarakat termasuk dialog, lokakarya, dan pelatihan. (Badranaya, 2016).

Model pembelajaran masyarakat yang dilaksanakan menerapkan model pembelajaran kooperatif terstruktur yang mengedepankan 5 unsur yaitu saling ketergantungan positif, interaksi tatap muka, tanggungjawab individu, komunikasi antar anggota, dan evaluasi

\section{DAFTAR PUSTAKA}

Andrias, M. A. dan Satori, A.(2016).Studi Pemetaan dan Pemecahan Masalah dalam Implementasi Pendidikan Karakter pada Institusi Pendidikan di Kota Tasikmalaya. Jurnal JIPP, 2(1),83-99 proses. (Maryani, Mustofa \& Dwi, 2018 ; Bukit, 2016).

Berdasarkan hasil pengabdian
pada masyarakat ini diharapkan menghasilkan tindak lanjut sebagai berikut :Pertama, Santri tidak hanya diajarkan mengenai ilmu agama (spiritual), santri juga di harapkan dibekali ilmu pemerintahan tentang bagaimana cara memimpin masyarakat dan pemerintahan yang baik; kedua, Peningkatan kesadaran akan wawasan kebangsaan harus senantiasa di pupuk dan ditumbuh kembangkan pada santri dengan berbagai upaya, antara lain pengenalan kembali simbol-simbol Negara, pemahaman terhadap pancasila sebagai dasar Negara; ketiga, Mengembangkan model pendidikan bela negara bagi santri khusus dan menanamkan jiwa patriotisme dan cinta terhadap tanah air; keempat, Mengembangkan metode pendidikan, penataran dan pelatihan di masyarakat baik di lingkungan pendidikan, di lingkungan pesantren; kelima, Perlu adanya kebijakan serius dari pemerintah mengenai deradikalisasi di kalangan pesantren.

\section{SIMPULAN}

Pemberdayaan masyarakat dalam bentuk pengabdian pada masyarakat dengan metode pembelajaran inidapat meningkatkan kesadaran berbangsa dan bernegara pada santri dan pelajar di pesantren-pesantren di Kecamatan Cikalong Kabupaten Tasikmalaya. Melalui kegiatan dialog dan Pelatihan pendidikan wawasan kebangsaan bela negara sehigga berimplikasi positif pada pengamalan nilainilai kebangsaan dalam kejidupan seharihari.

Badranaya, J. (2016). Petunjuk Teknis Pelaksanaan Pengabdian Masyarakat oleh Dosen Tahun Anggaran 2016.Jakarta : PPM LP2M UIN SAHID Jakarta.

Basri, H. (2001). Pesantren: Karakteristik dan Unsur-unsur kelembagaan, 
dalam Buku Sejarah Pertumbuhan dan Perkembangan Lembagalembaga Pendidikan Islam di Indonesia. Jakarta: Grasindo.

BPS Kabupaten Tasikmalaya 2016.

Budiwibowo, S. (2016).Revitalisasi Pancasila dan Bela Negara dalam Menghadapi Tantangan Global Melalui Pemb elajaran Berbasis Multikultural. Citizenship : Jurnal Pancasila dan Kewarganegaraan, 4(2), 565-585.

Bukit, H. (2016). Meningkatkan Motivasi Belajar Siswa dengan Menggunakan Model Kooperatif Tipe Student Teams Achievment Devision (STAD) Pada Mata Pelajaran IPS di Kelas V SDN 107402 Saentis. Elementary School Journal, 5 (2), 56-63.
Dhofier,Z.(2002). Tradisi Pesantren: Studi tentang Pandangan Hidup Kyai, Jakarta: LP3ES.

Maryani, I., Mustofa, A., \& Dwi, J.S.E., dkk, (2018). Evektifitas Pendampingan Kelompok Dalam Meningkatkan Motivasi Berwirausaha Peternak Sapi Perah. JPPM (Jurnal Pengabdian dan Pemberdayaan Masyarakat), 2(1), 7-13.

Mustofa, I. (2012). Pondok Pesantren dan Godaan Politik Pilkada, Lampung Post. 12 Februari 2010

Sulistyaningtyas, T., dkk. (2015). Sinergitas Paradigma Lintas Sektor di Bidang Keamanan dan Keselamatan Laut.Jakarta : PT Gramedia.

Wikipedia/pesantren/tasikmalaya. (di akses pada 16 Oktober 2017) 